\title{
PENGARUH LATIHAN PLIOMETRIK LOMPAT KODOK (FROG LEAPS) DAN DEPTH JUMPS TERHADAP POWER OTOT TUNGKAI PESILAT REMAJA SMP NEGERI 1 CIKALONGKULON
}

\author{
Kusnindar Samsu \\ Pendidikan Jasmani Kesehatan dan Rekreasi \\ Universitas Suryakancana, Fakultas Keguruan dan Ilmu Pendidikan \\ Kusnindarsamsu@gmail.com
}

\begin{tabular}{l}
\hline Info Artikel \\
\hline Sejarah Artikel: \\
Diterima Juni 2018 \\
Disetujui Oktober 2018 \\
Dipublikasikan Desember \\
2018
\end{tabular}

Abstrak

Tujuan penelitian adalah untuk: 1) Mengetahui pengaruh latihan pliometrik lompat kodok (frog leaps) terhadap power otot tungkai. 2) Mengetahui pengaruh latihan pliometrik depth jumps terhadap power otot tungkai. 3) Mengetahui perbedaan pengaruh model latihan pliometrik lompat kodok (frog leaps) dan depth jumps terhadap power otot tungkai. Populasi dan sampel yang diteliti pada penelitian ini sebanyak 20 Siswa usia 13-15 Tahun SMP Negeri 1 Cikalongkulon, populasi yang berjumlah 20 diambil keseluruhan sebagai sampel. Untuk variabel bebas penelitian adalah latihan pliometrik lompat kodok (frog leaps) dan depth jumps, Sedangkan variabel terikat dalam penelitian ini adalah power otot tungkai. Penelitian ini merupakan penelitian eksperiman lapangan dan desain penelitian ini menggunakan uji $-\mathrm{t}(\mathrm{t}-\mathrm{test})$. Uji t dua sampel dibagi kedalam dua jenis yaitu uji t dua sampel (dependent) berpasangan paired t-test (befor-after) dan $\mathrm{t}$ dua sampel/kelompok independent (bebas). Kesimpulan penelitian ini: 1) Terdapat pengaruh latihan pliometrik lompat kodok (frog leaps) terhadap power otot tungkai.2) Terdapat pengaruh latihan pliometrik depth jumps terhadap power otot tungkai. 3) Tidak terdapat perbedaan yang signifikan antara hasil latihan pliometrik lompat kodok (frog leaps) dengan depth jumps terhadap power otot tungkai, atau dengan kata lain pengaruh latihan lompat kodok sama dengan pengaruh latihan depth jumps terhadap power otot tungkai.

Keyword:

\section{Abstrack}

The objectives of the study were to: 1) Determine the plyometric jump training (frog strength) research on leg muscle strength. 2) Determine the effect of depth jump plyometrics exercises on leg muscle strength. 3) Determine the difference in the effect of the plyometric jump training model (frog jump) and deep jump on leg muscle strength. The population and sample issued in this study were 20 students aged 13-15 years of SMP Negeri 1 Cikalongkulon, the population collected 20 were taken as a whole sample. The independent variable of the study was the plyometric training of frog jumps (frog jumps) and deep jumps, while the research variables in this study were leg muscle strength. This research 
is a field experimental study and the design of this study uses $t$ test ( $t$-test). The two sample t-test is divided into two types, namely the two-sample t-test (dependent) paired paired t-test (befor-after) and t two samples / independent group (free). Conclusions of this study: 1) There is a plyometric jump training (frog strength) training on leg muscle strength. 2) Plyometric depth training is needed for leg muscle strength. 3) There is no significant difference between the results of plyometric exercises toad jump (frog jump) with the depth of jumping on leg muscle strength, or in other words

(C) 2018 Universitas Suryakancana

\footnotetext{
Alamat korespondensi:

E-mail:

Adirahadian@unsur.ac.id
}

\section{PENDAHULUAN}

Latihan merupakan suatu proses yang sistematik untuk meningkatkan kualitas fisik dan bertujuan untuk meningkatkan penampilan olahraga. Untuk itu metode latihan menjadi sengat penting bagi seorang pelatih. Latihan menjadi sangat efektif jika dilakukan dengan program yang baik. Kondisi fisik adalah satu kesatuan utuh dari komponen-komponen yang tidak dapat dipisahkan begitu saja, komponen kondisi fisik tersebut terdiri atas kekuatan, kecepatan, kelincahaan, kelentukan, dayatahan, daya ledak otot, koordinasi, keseimbangan, daya lentur, dan reaksi. Berkenaan dengan hal ini Harsono (2001:4) menjelaskan sebagai berikut:

Latihan kondisi fisik memegang peranan yang sangat penting dalam program latihan atlet, terutama atlet pertandingan. Istilah latihan kondisi fisik mengacu kepada suatu program latihan yang dilakukan secara sistematis, berencana dan progresif, dan yang

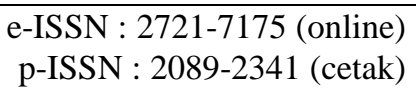

tujuannya ialah untuk meningkatkan kemampuan fungsional dari seluruh

sistem tubuh agar dengan demikian prestasi atlet semakin meningkat.

Dalam olahraga pencak silat daya ledak otot amat berperan penting dalam menunjang prestasi atlet. Kecepatan dan kekuatan menjadikan power yang menghasilkan ledakan keras pada tendangan dari atlet pencak silat. Harsono (2001:24) menjelaskan bahwa: "Power adalah produk dari kekuatan dan kecepatan. Power adalah kemampuan otot untuk mengarahkan kekuatan maksimal dalam waktu yang singkat". Dengan demikian daya ledak tendangan dalam olahraga pencak silat yang turut dipengaruhi oleh tungkai kaki sangat perlu untuk dilatih sejak dini sehingga perlu adanya latihan yang khusus untuk meningkatkan power tungkai tersebut.

Pembinaan fisik, teknik, maupun taktik dan mental tidak lepas dari latihan itu sendiri. Kemampuan power tungkai merupakan salah satu faktor terpenting untuk mendukung prestasi seorang atlet pencak silat. Metode latihan power tungkai sudah banyak diketahui oleh para pelatih namun model 


\section{3 | Kusnindar Samsu}

Pengaruh Latihan Pliometrik Lompat Kodok (Frog Leaps) Dan Depth Jumps

Terhadap Power Otot Tungkai Pesilat Remaja Smp Negeri 1 Cikalongkulon

latihan yang sangat monoton dapat mempengaruhi kejenuhan atlet yang mengakibatkan kurangnya rasa senang pada saat latihan dan hal ini mengakibatkan latihan yang tidak maksimal. Power tungkai seorang pesilat berperan penting guna menghasilkan kecepatan dan kekuatan maksimal. Untuk mencapai prestasi dalam olahraga pencak silat diperlukan berbagai pertimbangan dan perhitungan serta analisis yang cermat, sebagai faktor-faktor penentu dan penunjang prestasi tersebut dapat dijadikan dasar dalam menyusun program. Salah satu penunjang dalam prestasi pencak silat tersebut di antaranya adalah metode latihan. Agar proses latihan yang dipergunakan untuk meningkatkan kualitas fisik tidak menyita waktu yang juga dipergunakan untuk meningkatkan kualitas teknik dan taktik, maka perlu pengembangan metode latihan. Melalui pengembangan metode latihan yang tepat, diharapkan kualitas fisik dapat meningkat sejalan dengan meningkatnya kualitas teknik dan psikis para pesilat secara bertahap.

Dalam olahraga pencak silat seorang atlet dengan power tungkai tinggi akan lebih menguntungkan karena akan mudah dalam menerapkan teknik selama pertandingan. Teknik tendangan dalam pencak silat sangat dipengaruhi oleh kualitas otot tungkai dari pesilat. Untuk dapat melakukan teknik tendangan dengan baik diperlukan unsur kekuatan dan kecepatan dari sekelompok otot yang mendukung gerakan tersebut. Dari sekelompok otot yang paling dominan mendukung terhadap gerakan tendangan adalah otot tungkai. Oleh karena itu pemberian latihan yang diterapkan kepada pesilat sangat tepat kalau mengutamakan pada otot tungkai, dengan tidak mengesampingkan otot-otot yang lain.

Salah satu jenis metode latihan untuk meningkatkan power adalah dengan latihan Pliometrik. Seperti dijelaskan oleh Johansyah Lubis (2005:1) bahwa: "Latihan pliometrik adalah salah satu latihan yang favorit yang dilakukan oleh pelatih saat ini, terutama kepada cabang olahraga yang membutuhkan kemampuan dayaledak otot tungkai atau otot lengan”. Banyak jenis dan model latihan untuk meningkatkan power tungkai, Pliometrik merupakan metode latihan yang sering digunakan untuk meningkatkan eksplosif power khususnya pada cabang olahraga pencak silat. Model latihan Pliometrik merupakan bentuk latihan yang mempunyai tujuan yang sama yaitu melatih kemampuan power tungkai. Pada usia remaja power tungkai amat perlu dilatihkan, dalam kategori tanding pada usia remaja banyak sekali kemenangan yang dihasilkan melalui satu serangan secara berturut-turut dengan cepat dan kuat. Hal ini terlihat jelas tendangan yang memiliki power yang besar sangat berpengaruh pada permainan tingkat remaja. Sehubungan dengan uraian di atas bentuk latihan Pliometrik perlu dikembangkan agar dapat digunakan dalam berbagai cabangcabang olahraga, khususnya pencak silat.

Melihat dari permasalahan tersebut, maka peneliti ingin melakukan penelitian untuk mengetahui pengaruh latihan Pliometrik model lompat kodok (frog leaps) dan depth jumps terhadap power tungkai pesilat remaja putera SMP Negeri 1 Cikalongkulon Cianjur.

\section{METODE PENELITIAN}

Metode penelitian adalah cara yang digunakan oleh peneliti dalam mengumpulkan 


\section{4 | Kusnindar Samsu}

Pengaruh Latihan Pliometrik Lompat Kodok (Frog Leaps) Dan Depth Jumps

Terhadap Power Otot Tungkai Pesilat Remaja Smp Negeri 1 Cikalongkulon

data penelitiannya (Suharsimi Arikunto, 2006:160). Berdasarkan pengertian tersebut, metode dalam suatu penelitian merupakan salah satu cara yang ditempuh untuk mencapai suatu tujuan, sedangkan tujuan dalam sebuah penelitian adalah untuk mengungkapkan, menggambarkan, dan mengumpulkan hasil pemecahan melalui cara tertentu sesuai dengan prosedur penelitian yang dilakukan. Dengan demikian maka dapat dikatakan peneliti di dalam menerapkan metode penelitian menggunakan instrumen atau alat, agar data yang diperoleh lebih baik.

\section{POPULASI DAN SAMPEL}

\section{Populasi}

Populasi adalah keseluruhan subjek penelitian (Arikunto, 2006:130). Berdasarkan pendapat di atas berarti apabila ingin meneliti semua elemen yang ada dalam wilayah penelitian, maka penelitiannya merupakan penelitian papulasi.

Populasi dalam peneltian ini adalah atlet Pencak Silat Remaja SMP Negeri 1 Cikalongkulon Cianjur.

\section{Sampel}

\section{Suharsimi Arikunto (2006:131)} berpendapat bahwa sampel adalah sebagian atau wakil populasi yang diteliti.

Sampel dalam penelitian ini adalah 20 atlet pencak silat Remaja putera SMP Negeri 1 Cikalongkulon Cianjur tahun 2016.

\section{HASIL PENGOLAHAN DAN ANALISIS}

\section{DATA}

1. Uji Beda Rata-rata Sampel Berpasangan atau Paired t-test (Before After)
1.1 Untuk Mengetahui Pengaruh Latihan Pliometrik Lompat Kodok (Frog Leaps) Terhadap Power Otot Tungkai

Tabel 4.8

Hasil t-test Pre Test dan Post

Test Latihan Lompat Kodok

\begin{tabular}{|c|c|c|c|c|c|c|}
\hline $\begin{array}{c}\text { Data } \\
\text { Sampel }\end{array}$ & $\sum \mathrm{D}$ & & $\begin{array}{c}\mathrm{df} \\
= \\
\mathrm{n}- \\
1\end{array}$ & $\mathrm{t}_{\text {hitung }}$ & $\mathrm{t}_{\text {tabel }}$ & Signifikansi \\
\cline { 1 - 3 } $\begin{array}{c}\text { Pre } \\
\text { Test }\end{array}$ & \multirow{2}{*}{$\begin{array}{c}\text { Post } \\
\text { Test }\end{array}$} & 917 & 9 & $\begin{array}{c}- \\
23.668\end{array}$ & 2.26 & $\begin{array}{c}\text { Ada } \\
\text { Perbedaan }\end{array}$ \\
\cline { 1 - 2 }
\end{tabular}

Sumber : Hasil penelitian

Tahun 2015

Jika $\alpha=0,05$ dan $\mathrm{df}=\mathrm{n}-1$,

maka $t_{\text {table }}=t_{(1-1 / 2 \kappa)(n-1)}=$

$t_{(1-1 / 2 \pi)(10-1)}=t_{(0.975)(9)}=$

2.26

Sumber : Hasil Penelitian 2015

Dikarenakan $t_{\text {hitung }}$ berada diluar daerah penerimaan $\mathrm{H}_{\mathrm{o}}$, maka dapat disimpulkan bahwa $\mathrm{H}_{\mathrm{o}}$ ditolak, yaitu terdapat perbedaan yang signifikan antara sebelum dan sesudah latihan lompat kodok terhadap power otot tungkai. Atau latihan lompat kodok memberikan pengaruh yang signifikan terhadap peningkatan power otot tungkai

1.2 Untuk Mengetahui Pengaruh Latihan Pliometrik Depth Jumps Terhadap Power Otot Tungkai

Tabel 4.9 


\section{5 | Kusnindar Samsu}

Pengaruh Latihan Pliometrik Lompat Kodok (Frog Leaps) Dan Depth Jumps

Terhadap Power Otot Tungkai Pesilat Remaja Smp Negeri 1 Cikalongkulon

Hasil t-test Pre Test dan Post

Test Latihan Depth Jumps

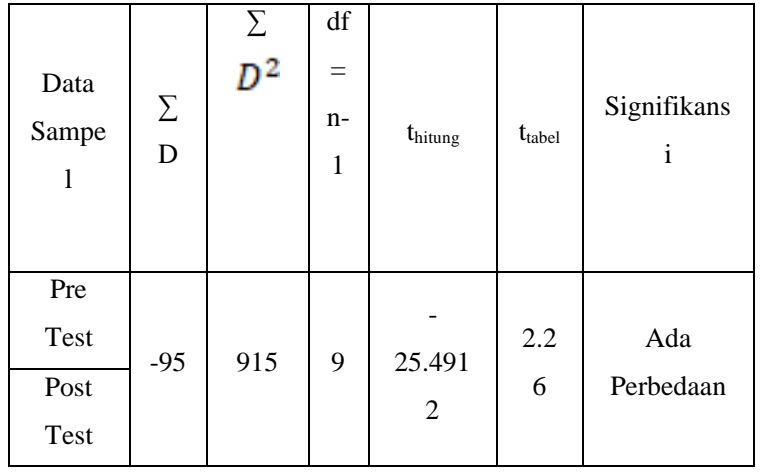

Sumber : Hasil penelitian

Tahun 2015

Jika $\alpha=0,05$ dan $\mathrm{df}=\mathrm{n}-1$,

maka $t_{\text {table }}=t_{(1-1 / 2 \kappa)(n-1)}=$

$t_{(1-1 / 2 \kappa)(10-1)}=t_{(0.975)(9)}=$

\subsection{6}

Dikarenakan $t_{\text {hitung }}$ berada diluar daerah penerimaan $\mathrm{H}_{\mathrm{o}}$, maka dapat disimpulkan bahwa $\mathrm{H}_{\mathrm{o}}$ ditolak, yaitu terdapat perbedaan yang signifikan antara sebelum dan sesudah latihan Depth Jumps terhadap power otot tungkai. Atau latihan lompat kodok memberikan pengaruh yang signifikan terhadap peningkatan power otot tungkai

2. Uji Beda Rata-rata Dua Sampel Bebas (Independent)

Uji beda rata-rata dua sampel bebas (independent) ini untuk mengetahui perbedaan dua rata-rata dari kelompok yang berbeda dan perlakuan yang berbeda dalam penelitian ini adalah untuk mengetahui perbedaan antara pengaruh lompat kodok (Frog leaps) dan depth jumps terhadap power otot tungkai atlet pencak silat.

Tabel 4.10

Hasil t-test Post Test Latihan

Lompat Kodok dan Depth Jumps

\begin{tabular}{|c|c|c|c|c|c|c|}
\hline Kelompok & $\bar{X}$ & $S^{2}$ & $\begin{array}{l}\text { df } \\
= \\
n-2\end{array}$ & $\begin{array}{c}\mathrm{t}_{\text {hitun }} \\
\mathrm{g}\end{array}$ & $t_{\text {tabel }}$ & $\begin{array}{l}\text { Signifi } \\
\text { kansi }\end{array}$ \\
\hline $\begin{array}{l}\text { Lompat } \\
\text { Kodok }\end{array}$ & $\begin{array}{l}4 \\
8 . \\
3\end{array}$ & $\begin{array}{l}2 \\
2 . \\
0 \\
1\end{array}$ & \multirow{2}{*}{18} & \multirow{2}{*}{$\begin{array}{l}0.0 \\
933\end{array}$} & \multirow{2}{*}{$\begin{array}{c}2.100 \\
92\end{array}$} & \multirow{2}{*}{$\begin{array}{c}\text { Tidak } \\
\text { Ada } \\
\text { Perbed } \\
\text { aan }\end{array}$} \\
\hline $\begin{array}{l}\text { Depth } \\
\text { Jumps }\end{array}$ & $\begin{array}{l}4 \\
8 . \\
1\end{array}$ & $\begin{array}{l}2 \\
3 . \\
8 \\
8\end{array}$ & & & & \\
\hline
\end{tabular}

Sumber : Hasil penelitian Tahun

2015

Jika $\alpha=0,05$ dan $\mathrm{df}=\mathrm{n}-2$, maka

$\mathrm{t}_{\text {table }}=2.10092$

Dikarenakan $t_{\text {hitung }}$ berada didalam daerah penerimaan $\mathrm{H}_{\mathrm{o}}$, maka dapat disimpulkan bahwa $\mathrm{H}_{\mathrm{o}}$ diterima , yaitu tidak ada perbedaan yang signifikan atau dengan kata lain pengaruh latihan lompat kodok sama dengan pengaruh latihan depth jumps terhadap power otot tungkai.

\section{KESIMPULAN DAN SARAN}

\section{Kesimpulan}

Hasil pre test dan post test yang telah dilakukan dalam penelitian "Pengaruh Latihan Pliometrik Lompat Kodok (frog Leaps) dan Depth Jumps Terhadap Power Otot Tungkai Pada Atlet Pencak Silat Remaja SMP Negri 1 Cikalongkulon Cianjur" dapat ditarik kesimpulan sebagai berikut: 


\section{6 | Kusnindar Samsu}

Pengaruh Latihan Pliometrik Lompat Kodok (Frog Leaps) Dan Depth Jumps

Terhadap Power Otot Tungkai Pesilat Remaja Smp Negeri 1 Cikalongkulon

1.1 Terdapat pengaruh latihan pliometrik lompat kodok (frog leaps) terhadap power otot tungkai pada atlet pencak silat Remaja SMP Negeri 1 Cikalongkulon Cianjur.

1.2 Terdapat pengaruh latihan pliometrik depth jumps terhadap power otot tungkai pada atlet pencak Remaja SMPN 1 Cikalongkulon Cianjur.

1.3 Tidak terdapat perbedaan pengaruh antara latihan pliometrik lompat kodok (frog leaps) dan Depth Jumps atau dalam arti kata lain pengaruh latihan lompat kodok sama dengan pengaruh latihan depth jumps, yaitu sama-sama memiliki pengaruh yang signifikan terhadap power otot tungkai pada atlet remaja putera SMP Negeri 1 Cikalongkulon Cianjur.

\section{Saran}

Hasil pre test dan post test yang telah dilakukan dalam penelitian "Pengaruh Latihan Pliometrik Lompat Kodok (frog Leaps) dan Depth Jumps Terhadap Power Otot Tungkai Pada Atlet Pencak Remaja SMP Negeri 1 Cikalongkulon Cianjur" dapat dikemukakan saran agar program latihan dapat menjadi lebih baik, diantaranya:

2.1 Sebaiknya para atlet senantiasa meningkatkan kondisi fisik dalam hal ini power otot tungkai untuk mencapai prestasi yang lebih baik salah satunya dengan latihan pliometrik lompat kodok (frog leaps) dan depth jumps.
2.2 Sebagai pelatih harus mampu mengkondisikan atlet pada saat berjalannya proses latihan dengan memberikan program latihan yang tepat kepada atletnya, salah satunya adalah pentingnya latihan Pliometrik lompat kodok (frog leaps) dan depth jumps dalam mendukung latihan kondisi fisik untuk meningkatkan prestasi para atlet pencak silat.

\section{DAFTAR PUSTAKA}

Arikunto, Suharsimi. 2006. Prosedur Penelitian : Suatu Pendekatan Praktek. Jakarta : Rineka Cipta.

Arikunto, Suharsimi. 2013. Prosedur Penelitian : Suatu Pendekatan Praktek.

Jakarta: Rineka Cipta

Departemen Pendidikan dan Kebudayaan Republik Indonesia. 2014. Buku Guru Pendidikan Jasmani Olahraga dan Kesehatan

Ery Pratiknyo Dwi Kusworo.2010. Tes Pengukuran Dan Evaluasi

Olahraga.Semarang:Widya Karya.

Dikdik Zafar Sidik. 2011. Materi Pengantar Kondisi Fisik (Strength and Conditioning). Cianjur.

Harsono. 2001. Latihan Kondisi Fisik. Bandung.

Rubianto Hadi. 2007. Ilmu Kepelatihan Dasar. Semarang:Rumah Indonesia. 


\section{$7 \mid$ Kusnindar Samsu}

Pengaruh Latihan Pliometrik Lompat Kodok (Frog Leaps) Dan Depth Jumps

Terhadap Power Otot Tungkai Pesilat Remaja Smp Negeri 1 Cikalongkulon

Mulyana. 2013. Pendidikan Pencak Silat :

Bandung : PT. Remaja Rosda Karya

Lubis, Johansyah. 2005. Mengenal Latihan Pliometrik. Online. Diakses tanggal 22/01/2015. Diunduh dari http://ml.scribd.com/doc/81841013/4 -mengenal-latihan-pliometrik

Lubis, Johansyah. 2013. Buku Pencak Silat. Online. Diakses tanggal 23/01/2015. Diunduh dari http://johansyahlubis.blogspot.com/2 013/12/buku-pencak-silat.html

Setiawan. 2008. Pengantar Statistika. Bandung. Online. Diakses tanggal (25/01/2015). Diunduh dari http://file.upi.edu/Direktori/FPBS/JU R._PEND._BAHASA_JERMAN/195 906231987031-

SETIAWAN/PS_12.pdf

Santoso. 2012. Metode Analisis Data. Online (25/01/2015). Diunduh dari http://ssantoso.umpo.ac.id/wpcontent/uploads/2012/03/BAB-IV.METODE-ANALISIS-DATA.pdf

Internet online $(23 / 01 / 2015)$. Otot. (http://id.wikipedia.org/wiki/Pencak_ silat)

Mashuri, Hendra. 2012. Depth Jumps. Online $(22 / 01 / 2015)$ (http://kopibangil.blogspot.com.html)
Mashuri, Hendra. 2012. Internet online $(22 / 01 / 2015)$ (http://kopibangil.blogspot.com/2012 /07/pliometrik.html).

Setiawan, Nasrul. 2013. Uji t Perbedaan Ratarata Dua Kelompok Berpasangan Online $(26 / 01 / 2015)$ (http://statisticeria.blogspot. com)

Internet online (23/01/2015). Tips Latihan Membentuk Otot Kaki Yang Kuat (http://duniafitnes.com/trainingplans/tips-latihan-membentuk-ototkaki-yang-kuat.html)

Internet online (23/01/2015). Pengertian Pliometrik dan Prinsip Latihan Pliometrik (http://mariberkawand.blogspot.com/2014/06/pe ngertian-pliometrik-dan-prinsip.html)

Internet online (23/01/2015). Otot. (http://id.wikipedia.org/wiki/Otot)

Internet online (23/01/2015). Tungkai. (http://kamuskesehatan.com/?s=tung kai)

Ferdian, Bobby. 2012. Internet online $(23 / 01 / 2015)$ (http://bobbyferdianmpd.blogspot.co m/2012/08/pliometrik.html)

Agus Susworo Dwi Marhaendro. Analisis Beda. Online (28/01/2015). Diunduh dari

(http://staff.uny.ac.id/sites/default/file s/Analisis\%20Beda.pdf) 


\section{8| Kusnindar Samsu}

Pengaruh Latihan Pliometrik Lompat Kodok (Frog Leaps) Dan Depth Jumps

Terhadap Power Otot Tungkai Pesilat Remaja Smp Negeri 1 Cikalongkulon

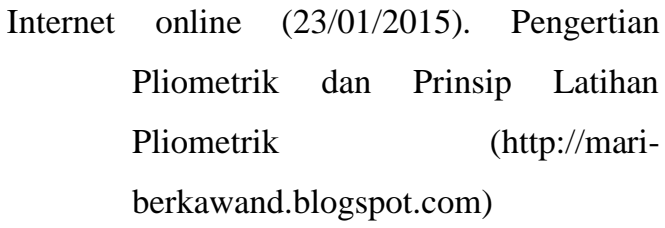

Internet online (23/01/2015). Macam Macam

Otot

Manusia.

(http://www.pustakasekolah.com/mac am-macam-otot-manusia.html) 